\title{
Completeness in Information Systems Ontologies
}

\author{
Timothy Tambassi ${ }^{1}$ iD
}

Received: 8 June 2021 / Accepted: 4 September 2021 / Published online: 16 September 2021

(c) The Author(s) 2021

\begin{abstract}
In the domain of information systems ontologies, the notion of completeness refers to ontological contents by demanding that they be exhaustive with respect to the domain that the ontology aims to represent. The purpose of this paper is to analyze such a notion, by distinguishing different varieties of completeness and by questioning its consistency with the open-world assumption, which formally assumes the incompleteness of conceptualizations on information systems ontologies.
\end{abstract}

Keywords Ontological completeness · Information systems ontologies · Open-world assumption $\cdot$ Closed-world assumption

\section{Ontological Completeness in the Philosophical Debate}

According to Cumpa (2019a: 152), an uncritical belief which silently encompasses the categorial debate from Plato to contemporary substantialists ${ }^{1}$ is that

(1) the completeness of systems of ontological categories should be (somehow) justified.

By "completeness", Cumpa (2019b: 6-7) refers to three different criteria of adequacy, which Thomasson (2019) presents as follows:

(2) comprehensiveness, that is, providing, at a high level of abstraction, categories for everything there is (or might be);

\footnotetext{
1 See in particular Aquinas (1952a, 1952b), Aristotle (1952), Britus (1981), Grossmann (1992), Hartmann (1953), Heil (2012), Kant (1965), Lowe (2006), Parmenides (1984), Plato (1997), Plotinus (19681988), Porphyry et al. (1993), Ryle (1938), Simplicius (1907).

Timothy Tambassi

timothy.tambassi@gmail.com

https://timothytambassi.wordpress.com/

1 Lecturer in Medieval Philosophy, Department of Science of Cultural Heritage, University of Salerno, via Giovanni Paolo II, 132, 84084 Fisciano, SA, Italy
} 
(3) exhaustivity, which indicates that whatever there is (or might be) should find its place in one and only one category;

(4) hierarchical organization, according to which no category can be in more than one level in the hierarchy of ontological system.

(1), Cumpa maintains, depends upon

(5) the difficulty substantialism faces in accounting for relations among enumerated categories.

This means, if (1) and (5) both hold, then

(6) the completeness of systems of categories is not a problem for categorial ontology in general, but just for substantialism.

Therefore, other philosophical traditions (such as factualism or reductionism) which do not consider the world as an enumeration (but, for examples, as a combination) of categories do not have to deal with the issue of completeness (see also Thomasson 2019).

Smith (2003) seems to confirm (6), by remarking that, in approaching the ontological investigation, different philosophical perspectives may follow/be based on different assumptions. Examples of those assumptions are, among others, the same notion of completeness specified by (2), (3) and (4), and the notion of ontological economy, which is further divided, by Fiddaman and Rodriguez-Pereyra (2018), into two different versions:

(7) qualitative economy asserting to do not multiply types of entities without necessity,

(8) quantitative economy claiming to do not multiply token entities without necessity. $^{2}$

The existence of different assumptions does not imply that diverse philosophical approaches cannot integrate/mix such assumptions. For example, one could sketch a parsimonious ontology that does not multiply types of entities without necessity (cf. (7)) and that aims to be exhaustive (cf. (3)).

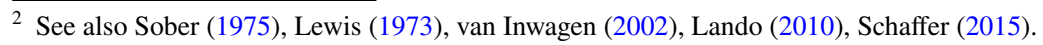




\section{Completeness in Information System Ontologies}

The notion of completeness is not, however, monopoly of ontological philosophy. Computer science, for example, has internalized and adapted such a notion to the peculiarity of its own area of investigation ${ }^{3}$ - an area that, ontologically speaking, can be divided into (at least) two different sub-branches.

(9) The first one deals with problems concerning specification, programming, implementation, verification, and testing of computational systems, which are traditionally seen as composed of two ontologically distinct entities: software and hardware

(10) The second sub-branch concerns information systems ontologies [ISOs], conceived as formal representations of conceptualizations aimed at representing and systematizing the contents of a specific domain of interest, and making such contents processable (also) by artificial agents. ${ }^{5}$

Within (10), the debate on the notion of completeness (and on some related notions such as informativeness, accessibility, and repeated applicability) ${ }^{6}$ has mainly ranged

(11) from questions regarding (11.1) the (kinds of) entities populating ISOs, (11.2) formal relations among those entities, and (11.3) their systematizations among ISOs' core-components, ${ }^{7}$

(12) to issues regarding the explicitation of methodology and theoretical choices for delineating and circumscribing the domain of interest that an ISO is meant to represent and systematize. ${ }^{8}$

In such a context, the notion of completeness has also shown that philosophical ontology and ISOs present analogies and discrepancies. ${ }^{9}$ Discrepancies mainly refer to the aims of these two ontological investigations.

(13) Philosophical (especially, analytical) ontology aims to outline a complete (cf. (2), (3) and (4)) inventory of what there is or might be, ${ }^{10}$ by specifying its hierarchical and categorial structure. ${ }^{11}$

\footnotetext{
3 See Gruber (1995), Smith (2003).

4 See Turner et al. (2019), Turner (2019), Primiero (2020).

5 See Gruber (1993); Guarino and Giaretta (1995); Breitman et al. (2007); Guarino and Musen (2015).

6 See Pâslaru-Bontaş (2007), Munn (2008), Goy and Magro (2015), Couclelis (2019).

7 For an analysis of the ISOs' core components, see Noy and McGuinness (2003); Jaziri and Gargouri (2010); Tambassi (2021a).

8 See Holsapple and Joshi (2002); Laurini (2017); Tambassi (2021b).

9 See Cumpa (2019a); Tambassi (2021a).

10 See Quine (1948), Varzi (2005).

11 See Lowe (2002), Westerhoff (2005).
} 
(14) ISOs circumscribe the inventory within the aims for which a specific ISO has been developed. Such aims, which (can) vary from ISO to ISO, ${ }^{12}$ define the domain (and the point of view) that an ISO represents.

In light of such discrepancy, it is not surprising that the notion of ISOs completeness [IC] is closely related to (and may depend on) the heterogeneity of ISOs' aims, a heterogeneity that does not prevent the debate on ISOs $^{13}$ from identifying a common ground for this notion, that is:

(15) ISOs' completeness [IC] is such that ISO's contents should be exhaustive for the (specific) domain that an ISO aims to represent.

Analogous to philosophical completeness, "exhaustive" (in (15)) refers to the fact the whatever an ISO aims to represent should find its place among the contents (the entities) of the ISO (cf. (3) and (11.1)). And such contents should be ultimately located among the ISO's core components (cf. (11.3)]), ${ }^{14}$ which provide the final IT structure of the ISO, just like the (philosophical) criterion of comprehensiveness (cf. (2)) suggests for ontological categories.

\section{On Information System Ontologies' Aims and Domains to Represent}

If, as we said, IC is related to ISOs' aims (cf. (15)) and those aims can vary from ISO to ISO (cf. (14)), then also IC could, in principle, vary depending on the aim of a specific ISO. To clarify this point, let us suppose to build an ISO, ISOntology ${ }_{1}$, aimed at relating every person employed in a specific philosophy department to their job position(s) within the department at time ${ }_{1}$. According to (15), ISOntology respects IC if and only if all employees and job positions are included in ISOntol$o g y_{1}$. In other words, IC is guaranteed in ISOntology $y_{1}$ if, for example,

(S1) the component of instances ${ }^{15}$ contains the totality of people employed in that department at time ${ }_{1}$, and the component of classes $^{16}$ includes all the job positions of the department at time .

\footnotetext{
12 See Guarino and Giaretta (1995), Adams and Janowicz (2011), Janowicz and Hitzler (2012), Guarino (2018).

13 See Bittner and Smith (2008).

14 For a list of ISOs' core components, see Lord (2010); Laurini (2017).

15 "Instances" are the lowest level components of an ISO and may model concrete objects such as laptops or planets, or more abstract objects such as numbers, concepts or functions (cf. Laurini 2017).

16 "Classes" represent groups or sets of different instances sharing common features. Classes can also contain (more specific) sub-classes and/or be sub-classes of other (less specific) classes (cf. Jaziri and Gargouri 2010).
} 
Such an example does not exclude, for ISOntology $y_{1}$ (as well as for any ISO), the chance that/of:

(16) classes and instances can (also) be characterized by slots, ${ }^{17}$ which specify the properties of each job position (e.g., "duration of assignment", "date of hire", etc.) and of the actual employee ("gender", "age", and so forth);

(17) alternative systematizations, within which, in order to guarantee IC, all the job positions and all the people employed in the department must still be located among ISOs' components - regardless of which components.

Suppose now to build an ISO, ISOntology $y_{2}$, aimed at classifying the known (biological) species. According to (15), ISOntology $y_{2}$ respects IC if and only if such species find their place among the contents of ISOntology2. And without precluding the possibility of alternative systematizations (cf. (17)), this could occur if, for example,

(S2) all the known species are included among the ramifications of the component of classes.

Now, both S1 and S2 intend to pursue IC in relations to the domains that, respectively, ISOntology $y_{1}$ and ISOntology $y_{2}$ aims to represent (cf. (15)). For ISOntology, the domain is restricted to the job positions and the people employed in a specific philosophy department at the time ${ }_{1}$. This means, ISOntology $y_{1}$ can be complete (and thus respects IC), even without including/specifying the (biological) species of the people employed in the department. Why? Because species do not fall within the domain of interest specified by the aims of ISOntology $y_{1}$. The same cannot be said ISOntology $y_{2}$ whose domain, in order to pursue IC, cannot disregard the inclusion of the species that ISOntology $y_{2}$ aims to represent.

\section{Varieties of ISO' Completeness}

Aims and domains of interest do not cover the differences between S1 and S2. Indeed,

(18) while S1 is grounded on the components of classes and instances, S2 makes no reference to instances: it only refers to the component of classes, which are supposed to cover all the different known species that ISOntology $y_{2}$ aims to represent.

S2's lack of references to instances does not represent a limit for meeting IC (cf. (14)).

\footnotetext{
17 "Slots" describe the various features of a class and its instances (Noy and McGuinness 2003). More precisely, slots "contribute to identify [classes] by characterizing them and can be used in intensional definitions of [classes], to relate [instances] or to give attribute values" (Jaziri and Gargouri 2010, p. 38).
} 
(19) Firstly, as for the aims of ISOntology $y_{2}$, adding instances would mean, for example, populating the classes of known species with their respective individual living beings. But such an inclusion would be ancillary because it is not required by the aims of ISOntology $y_{2}$.

(20) Secondly, ISOs need not to include instances. ${ }^{18}$ This means, although ISOs' contents are ultimately systematized among ISOs' components, ISOs' contents should not necessarily be systematized within the components of instances. Generalizing, IC is strictly connected to ISOs' components, but not to any specific component.

Now, despite the difference regarding the ISOs' components S1 and S2 refer to (cf. (18)), we can affirm that both S1 and S2 follow IC. Indeed, the domains of ISOntology $_{1}$ and ISOntology $y_{2}$ are exhaustively represented by the systematizations that $\mathrm{S} 1$ and $\mathrm{S} 2$ respectively provide. However, (18) seems to suggest that, although $\mathrm{S} 1$ and S2 are consistent with IC, they are consistent in a different way. To explain the difference, let us go back to the distinction between (6) and (7). Both (6) and (7) are consistent with the notion of ontological economy. More precisely, they represent two different versions of such economy: (6) concerns types of entities in a philosophical ontology, (7) concerns tokens. Analogously, we could distinguish different versions of IC, according to the ISO's components at stake. In other words, we can have.

(21) An IC based on the ISO's component of classes when the ISO's contents specified by classes are exhaustive for the domain that the ISO aims to represent (cf. S2); an IC based on the ISO's component instances when ISO's contents specified instances are exhaustive for the domain that the ISO aims to represent, and so forth.

(21) does not imply that different ISOs' components cannot be combined in order to meet IC (this is the case of S1, in which IC is obtained by the combination of instances and classes), neither that the list of ISOs' components will never change and so will the varieties of IC to which ISOs' components refer to. (21) would also explain why both S1 and S2 are consistent with IC, as well as why their consistency with IC is different, as IC can refer to different ISOs' components (cf. (18)).

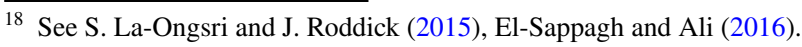




\section{Between Open-World and Closed-World Assumption}

The notion of IC is not accepted by the entire community of computer scientists. Indeed, especially for those ISOs using Semantic web languages such as OWL and RDFS, some IT approaches assume the incompleteness of ISOs' conceptualizations. ${ }^{19}$ Such an incompleteness is formally stated as

(22) the open-world assumption [OWA], according to which everything that cannot be inferred as false from an ISO must be considered unknown. ${ }^{20}$

(Conversely, in many programming languages and formal systems of logic ${ }^{21}$ used for knowledge representation, some IT approaches adopt the closed-world assumption [CWA], according to which, everything that is not known to be true, in the system, must be considered as false.) But then, how to interpret the incompleteness of OWA as compatible or incompatible with the notion of IC?

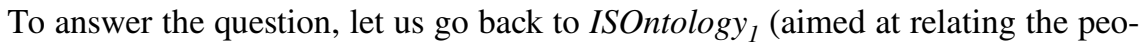
ple employed in a specific philosophy department, at time ${ }_{1}$, to their job position(s) within the department) and suppose that

(23) ISOntology $y_{1}$ contains only the totality of the job positions and of the people employed in that department of philosophy at time ${ }_{1}$.

Suppose then that,

(24) among the employees of the philosophy department at time ${ }_{1}$, ISOntology IS $_{1}$ includes Hypatia but not Kant, since he works at the biology department.

Let us finally ask ourselves:

(25) Does Kant work at the philosophy department at time ${ }_{1}$ ?

(26) Does Hypatia work at the philosophy department at time ${ }_{1}$ ?

(27) Does Kant work at the biology department at time ${ }_{1}$ ?

(28) Does Hypatia work at the biology department at time ${ }_{1}$ ?

As regards (25), we could say that OWA would answer "unknown": it is true that Kant is not included into ISOntology $y_{1}$ (cf. (24)), but he is not even formally excluded (cf. (23)). And, on the basis of (22), it may not be inferred as false that Kant works at the philosophy department at time ${ }_{1}$, but rather as unknown. IC, in contrast, answers "false" to (25) (just like CWA would do): (23) is exhaustive for the aim ISOntology and Kant is not included within the employees of the philosophy department (cf.

19 See Henley (2006), Porello and Endris (2014), Baader et al. (2017), Rector et al. (2019).

20 See Baader et al. (2004).

21 See Russell and Norvig (2020). 
(24)). To obtain the (same) answer, "false", from both OWA and IC, ISOntology should include, in addition to the people employed in the philosophy department, a constrain specifying that Kant is not part of the people employed by the philosophy department. This means, without such a constrain, OWA and IC are incompatible.

Conversely, (26) has the same answer, "true", both if we assume IC or OWA. More precisely, for OWA the answer to (26) cannot be "false" or "unknown" to the extent that ISOntology $y_{1}$ explicitly states that Hypatia works in that department at the time ${ }_{1}$ (cf. (24)). For IC, the answer is "true" because of the aim ISOntology ${ }_{1}$, an aim that is fulfilled by (23) and, especially, (24). Therefore, as regards the answer to (26), OWA and IC are not incompatible.

Finally, as for (27) and (28), we have the answers "unknown" from both OWA and IC. Specifically, OWA answers depend on the fact that ISOntology $y_{1}$ makes no claims on the employees of the biology department (cf. (23) and (24)); IC answers come from the fact that IC does not have any systematic answer for questions such as (27) and (28), which do not refer to the aim of ISOntology $y_{1}$. Thus, even in these cases, OWA and IC are not incompatible.

All this considered, we can affirm that IC is not entirely incompatible with the incompleteness of OWA. ${ }^{22}$ This means, an ISO could follow, in principle, both IC and OWA. However, observing both of them requires some specific adjustments in the ISO building, that is:

(29) indicating all the ISO's components involved with IC (cf. (17)),

(30) (and) adding to the ISO some constraints specifying that all and only those components should be treated under the closed-world assumption, just as the answer to (25) suggests. ${ }^{23}$

Funding Open access funding provided by Università degli Studi di Salerno within the CRUI-CARE Agreement.

\section{Declartions}

Conflict of interest On behalf of all authors, the corresponding author states that there is no conflict of interest.

Open Access This article is licensed under a Creative Commons Attribution 4.0 International License, which permits use, sharing, adaptation, distribution and reproduction in any medium or format, as long as you give appropriate credit to the original author(s) and the source, provide a link to the Creative Commons licence, and indicate if changes were made. The images or other third party material in this article are included in the article's Creative Commons licence, unless indicated otherwise in a credit line to the material. If material is not included in the article's Creative Commons licence and your intended use is not permitted by statutory regulation or exceeds the permitted use, you will need to obtain permission directly from the copyright holder. To view a copy of this licence, visit http://creativecommons.org/licen ses/by/4.0/.

\footnotetext{
22 See also Motro (1989), Razniewski et al. (2016).

23 See Lutz et al. (2012).
} 


\section{References}

Adams BJ, Janowicz K (2011) Constructing Geo-ontologies by Reification of Observation Data. In: Agrawal D, Cruz I, Jensen C, Oflek E, Tanin E (eds) GIS '11: Proceedings of the 19th ACM SIGSPATIAL International Conference on Advances in Geographic Information Systems, November 1-4, 2011 - Chicago, Illinois. ACM Press, Chicago, pp 309-318

Aquinas T (1952a) Commentaria in Octo Libros Physicorum. www.corpusthomisticum.org/iopera.html

Aquinas T (1952b) Sententia Libri Metaphysicae. www.corpusthomisticum.org/iopera.html

Aristotle (1952). Categories and De Interpretatione. Clarendon Press, Oxford. Translated by JL Ackrill

Baader F, Horrocks I, Lutz C, Sattler U (2017) An introduction to description logic. Cambridge University Press, Cambridge

Baader F, Horrocks I, Sattler U (2004) Description logics. In: Staab S, Studer R (eds) Handbook on ontologies. International Handbooks on Information Systems. Springer, Berlin, Heidelberg, pp 3-28

Bittner T, Smith B (2008) A theory of granular partitions. In: Munn K, Smith B (eds) Applied ontology. An introduction. Ontos-Verlag, Berlin

Breitman KK, Casanova MA, Truszkowski W (2007) Semantic web: concepts, technologies and applications. Springer, London

Britus R (1981) Quaestiones Super Librum Praedicamentorum (§viii). Cahiers De L’institut Du MoyenÂge Grec Et Latin 39:88-96

Couclelis H (2019) Unpacking the "I" in GIS: Information, ontology, and the geographic world. In: Tambassi T (ed) The Philosophy of GIS. Springer, Cham, pp 3-24

Cumpa J (2019a) Structure and completeness: a defense of factualism in categorial ontology. Acta Anal 34(2):145-153

Cumpa J (2019b) Categories. Philos Compass. https://doi.org/10.1111/phc3.12646

El-Sappagh S, Ali F (2016) DDO: a diabetes mellitus diagnosis ontology. Appl Inf. https://doi.org/10. 1186/s40535-016-0021-2

Fiddaman M, Rodriguez-Pereyra G (2018) The razor and the laser. Anal Philos 59(3):341-358

Goy A, Magro D (2015) What are ontologies useful for? In: Khosrow-Pour M (ed) Encyclopedia of information science and technology. IGI Global, Pennsylvania, pp 7456-7464

Grossmann R (1992) Existence of the world: an introduction to ontology. Routledge, London, New York

Gruber TR (1993) A translation approach to portable ontology specifications. Knowl Acquis 5(2):199-220

Gruber TR (1995) Toward principles for the design of ontologies used for knowledge sharing. Int J Human Comput Stud 43(5/6):907-928

Guarino N (2018) Formal Ontology and Information Systems. In: Proceedings of FOIS '98. June 06-08, Trento, Italy. IOS Press, Amsterdam, pp 3-15

Guarino N, Giaretta P (1995) Ontologies and knowledge cases-towards a terminological clarification. In: Mars NJ (ed) Towards very large knowledge bases-knowledge building and knowledge sharing. IOS Press, Amsterdam, pp 25-32

Guarino N, Musen M (2015) Applied ontology: the next decade begins. Appl Ontol 10:1-4

Hartmann N (1953) New ways of ontology. Henry Regnery Company, Chicago

Heil J (2012) The world as we find it. Oxford University Press, Oxford

Henley S (2006) The problem of missing data in geoscience databases. Comput Geosci 32:1368-1377

Holsapple CW, Joshi KD (2002) A Collaborative approach to ontology design. Commun ACM 45(2):477-490

Janowicz K, Hitzler P (2012) The Digital Earth as Knowledge Engine. Editorial. Semant Web 1(1):1-10

Jaziri W, Gargouri F (2010) Ontology theory, management and design: an overview and future directions. In: Gargouri F, Jaziri W (eds) Ontology theory, management and design: advanced tools and models. Information Science Reference. Hershey (PA), Pennsylvania, pp 27-77

Kant I (1965) Critique of the Pure Reason. St Martin Press, London. Translated by N Kemp Smith

Lando G (2010). Ontologia. Un'introduzione. Carocci, Roma

La-Ongsri S, Roddick J (2015) Incorporating ontology-based semantics into conceptual modelling. Inf Syst 52:1-20

Laurini R (2017) Geographic knowledge infrastructure: applications to territorial intelligence and smart cities. ISTE-Elsevier, London

Lewis D (1973) Counterfactuals. Blackwell, Oxford

Lord P (2010) Components of an ontology. http://ontogenesis.knowledge blog.org/514 
Lowe EJ (2002) A survey of metaphysics. Oxford University Press, Oxford

Lowe EJ (2006) The four-category ontology: a metaphysical foundation for natural science. Clarendon Press, Oxford

Lutz C, Seylan I, Wolter F (2012) Mixing open and closed world assumption in ontology-based data access: Non-uniform data complexity. In: Kazarov Y, Lembo D, Wolter (eds) Proceedings of the international workshop on description logics, DL 2021, CEUR Workshop Proceedings vol 846

Motro A (1989) Integrity = Validity Completeness. ACM TODS 14(4):480-502

Munn K (2008) Introduction: what is ontology for? In: Munn K, Smith B (eds) Applied ontology. An Introduction. Ontos-Verlag, Berlin, pp 7-19

Noy NF, McGuinness DL (2003) Ontology Development 101: a guide to creating your first ontology. Stanford University, Stanford (CA)

Parmenides (1984) On Nature. In: Gallop D (ed), Parmenides of Elea: Fragments. University of Toronto Press, Toronto

Pâslaru-Bontaş E (2007). A Contextual Approach to Ontology Reuse. Methodology, Methods and Tools for the Semantic Web. Ph.D. Thesis, Department of Mathematics and Computer Science, Freien Universitat, Berlin

Plato (1997) Sophist. In Cooper MJ (ed) Plato: Complete Works. Hackett, Indianapolis

Plotinus (1968-1988) On the Genera of Being. In: Enneads. Loeb Classical Library, Cambridge. Translated by AH Armstrong

Porello D, Endriss U (2014) Ontology merging as social choice: judgment aggregation under the open world assumption. J Log Comput 24(6):11229-11249

Porphyry (1993) In Platonis Sophistem Commentarii. In: Smith A et al (eds) Porphyrii Philosophi Fragmenta. Teubner, Leizpig, pp 164-195

Primiero G (2020) On the foundations of computing. Oxford University Press, Oxford

Quine WVO (1948) On what there is. Rev Metaphys 2:21-38

Razniewski S, Savkovic O, Nutt W (2016). Turning the Partial-Closed World Assumption Upside Down. In: Pichler R, Soares da Silva A (eds) Proceedings of the 10th Alberto Mendelzon International Workshop on Foundations of Data Management, Panama City, Panama, May 8-10, 2016. CEUR Workshop Proceedings 1644, CEUR-WS.org 2016

Rector A, Schulz S, Rodrigues JM, Chute CG, Solbrig H (2019) On Beyond Gruber: "Ontologies" in Today's biomedical information systems and the limits of OWL. J Biomed Inf X. https://doi.org/10. 1016/j.yjbinx.2019.100002

Russell SJ, Norvig P (2020) Artificial intelligence. A modern approach. Pearson Publications, London

Ryle G (1938) Categories. Proc Aristot Soc 38:189-206

Schaffer J (2015) What not to multiply without necessity. Australas J Philos 93:644-664

Simplicius (1907) In aristotelis categorias commentarium. In: Kalbfleisch C (ed) Commentaria in Aristotelem Graeca, vol 5. Reimer, Berlin

Sober E (1975) Simplicity. Oxford University Press, Oxford

Smith B (2003) Ontology. In: Floridi L (ed) Blackwell guide to the philosophy of computing and information. Blackwell, Malden, MA/Oxford/Carlton, pp 155-166

Tambassi T (2021a) The philosophy of geo-ontologies. Applied ontology of geography. Springer, Cham

Tambassi T (2021b) Intrecci Meta-ontologici tra Filosofia e Informatica. Giornale di metafisica, in press

Thomasson A (2019) Categories. In: Zalta EN (ed) The Stanford Encyclopedia of Philosophy. Summer, Delhi

Turner R (2019) Computational artifacts: towards a philosophy of computer science. Springer, Berlin, Heidelberg

Turner R, Angius N, Primiero G (2019) The Philosophy of Computer Science. In: Zalta EN (ed) The Stanford Encyclopedia of Philosophy, Spring

van Inwagen P (2002) Ontology, identity and modality: essays in metaphysics. Cambridge University Press, Cambridge

Varzi AC (2005) Ontologia. Laterza, Rome, Bari

Westerhoff J (2005) Ontological categories. Clarendon Press, Oxford

Publisher's Note Springer Nature remains neutral with regard to jurisdictional claims in published maps and institutional affiliations. 